\title{
Pulvinar Sign in Wernicke's Encephalopathy
}

\section{To the Editor:}

We present the case of a 39-year-old woman, who was reported to the German CreutzfeldtJakob-Disease (CJD) Surveillance Unit. Her magnetic resonance image (MRI) was suggestive of variant CJD (VCJD), which would have been the first case in Germany. The case is presented in detail and the differential diagnoses are discussed. The knowledge of these differential diagnoses is vital in order not to miss treatable causes of rapidly progressive dementias in clinical practice. This case serves as a reminder to consider Wernicke's disease in patients with rapid cognitive decline and multifocal neurological deficits.

\section{INTRODUCTION}

Progressive dementias in younger patients typically comprise a great number of differential diagnoses such as inflammatory, metabolic, and vascular diseases. ${ }^{1}$ Detailed clinical and diagnostic workup help to establish the correct diagnosis. Neurodegenerative early onset dementias, and familial or transmitted prion encephalopathies, are rare but should be considered.

\section{CASE REPORT}

A 39-year-old woman underwent a tonsillectomy for recurrent infections. After discharge from the department of otorhinolaryngology ( 5 days after surgery), she suffered from severe persistent dysphagia. She did not report to a doctor until 9 weeks after surgery, when she was admitted to a hospital with recurrent emesis and dehydration. At that time, she had lost weight $(92 \mathrm{~kg}$ to $67 \mathrm{~kg}$, height: $176 \mathrm{~cm}$ ). An esophago- gastro-duodenoscopy and a computed tomography (CT) scan of the abdomen did not reveal the etiology of the dysphagia. During her inpatient admission the dysphagia improved but she developed an organic psychosyndrome with apathy, lack of motivation, and visual disturbances, including temporary total anopsia. An ophtalmologic examination revealed a slight vertical nystagmus only. Cerebral CT and MRI were normal.

The patient was suspected to suffer from a dissociative disorder and therefore was referred to a psychiatric hospital. She was transferred shortly afterwards to the department of neurology of the reporting hospital ( 12 weeks after surgery). At this admission the patient was somnolent, hallucinating, and tachycardiac. She suffered from severe avolition, dysphonia, impaired memory, and formal thought disorder (as assessed by a Mini Mental Status Examination [MMSE] score of 22/30). Spontaneous nystagmus with high amplitude was present. The patient had a flaccid tetraparesis and was incontinent. Diagnostic tests were performed and a probatory treatment was started.

The German National Reference Center for the Surveillance of Transmissible Spongiform Encephalopathies (TSE) was notified a few days later when MRI fluid attenuation inversion recovery (FLAIR) imaging revealed bilateral medial thalamic hyperintensities consistent with the pulvinar sign (Figure 1) considered characteristic for VCJD. ${ }^{2}$ Upon notification, the patient and relatives were visited by a physician from the TSE Surveillance Unit for a detailed interview, physical examination, and discussion of the case with the treating physician ( 15 weeks after surgery). The patient was awake and oriented to 
situational qualities. Cognitive deficits mainly affected short-term memory (MMSE score: $25 / 30$ ). Spontaneous vertical upbeat nystagmus was present. The cranial nerve examination was otherwise normal. Dysmetria was apparent in all limbs as well as intention tremor in both arms. The patient was bedbound due to paraparesis of the lower extremities. Motor reflexes were all decreased and were not inducible at the lower extremities. No Babinski sign was provokable. Sensitivity was not impaired.

\section{Medical, Social, and Family History}

The patient had a history of allergic asthma and hyperlipidemia, nasal sinus surgeries 4 and 6 years before, a coccygeal fracture 14 years and pulmonary embolism 15 years before. She neither misused alcohol, nicotine, or illicit drugs nor did she take any medication prior to the tonsillectomy. She had not received blood transfusions, growth hormones, or heterologous grafts. The patient had never been in regular contact with cattle or chemicals such as solvents. She had never been to the United Kingdom nor had she lived abroad for any significant period of time. The family's medical history comprises allergic asthma, psoriasis, cerebrovascular disease, and colon cancer, but no early onset dementia or other severe neurologic or psychiatric disorder.

\section{Imaging, Laborafory Tests, Electrophysiological Tests}

An MRI FLAIR study revealed the pulvinar sign (Figure 1) and hyperintensity in the periaqueductal grey matter. A spinal MRI was normal. Generalized theta-activity but no triphasic waves or epileptic potentials were recorded on electroencephalography (EEG) (Figure 2). Celiac disease associated antibodies, paraneoplastic antineuronal antibodies, and thyreoperoxidase antibodies were within the normal range. Vitamin B1 level was $54 \mathrm{ng} / \mathrm{ml}$ (range: $20-100 \mathrm{ng} / \mathrm{ml}$ ), erythrocyte transketolase activity was decreased with $38 \mathrm{U} / \mathrm{L}$ (range: 60-85 U/L). Cerebrospinal fluid (CSF) was clear, and no signs of acute or chronic inflammation were present. Testing for Proteins 14-3-3 was negative. CSF Tau was not elevated (110 pg/ $\mathrm{ml}$ ). Neurography detected signs of recent axonal damage. Extra- and transcranial sonography excluded arterial stenosis or dissection.

\section{Management of the Case}

Important differential diagnoses of the MRI lesions were vCJD and Wernicke's Encephalopathy (WE). Familial prion diseases such as GerstmannStraeussler-Scheinker-Synrome or Fatal Familial Insomnia were also considered because of the patient's young age. She was supplemented with intravenous vitamin B1, B12, benfotiamine, and folic acid. Tachycardia was treated with $\beta$-blockers. A few days later, the cognitive status improved, the psychotic symptoms regressed, and the patient started to eat.

Results of prion protein (PRNP) codon 129 testing arrived showing methionine/valine (M/N) heterozygosity. This information made the diagnosis of VCJD appear unlikely because it has only been seen in methionine homozygous patients ${ }^{3}$ with one exception. Pathological changes related to VCJD in lymphatic tissue have been reported for one $\mathrm{M} N$ heterozygous patient who died early from a non-neurological disorder 5 years after having received blood from a vCJD patient. ${ }^{4}$

In the following weeks, the EEG activity accelerated, the MRI lesions improved, muscle strength returned, nystagmus subsided, and at 17 weeks after surgery, the patient was transferred into a rehabilitation unit. In week 18 after surgery the patient still had some cognitive impairment but was again able to sit, and to control bladder and bowel function. Further genetic

\section{FIGURE 1. \\ Cerebral MRI FLAIR axial sequence}

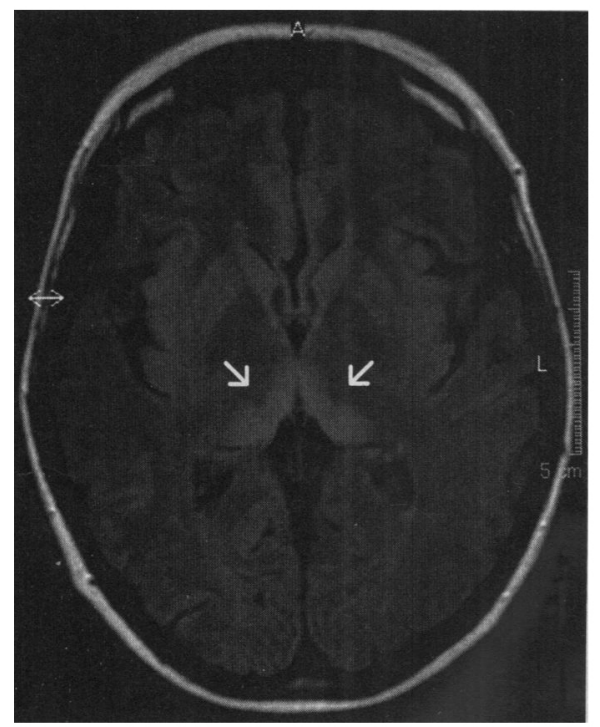

The pulvinar sign is marked by arrows.

MRI=magnetic resonance image; FLAIR=fluid attenuation inversion recovery.

Schmidt C, Plickert S, Summers D, Zerr I. CNS Spectr. Vol 15, No 4. 2010. 
testing for familial forms of prion disorders (PRNP sequencing) was not considered useful due to the negative family history and successful response to treatment of thiamine deficiency.

\section{DISCUSSION}

VCJD is a transmissible prion disorder associated with consumption of contaminated meat from cattle suffering from the Bovine Spongiform

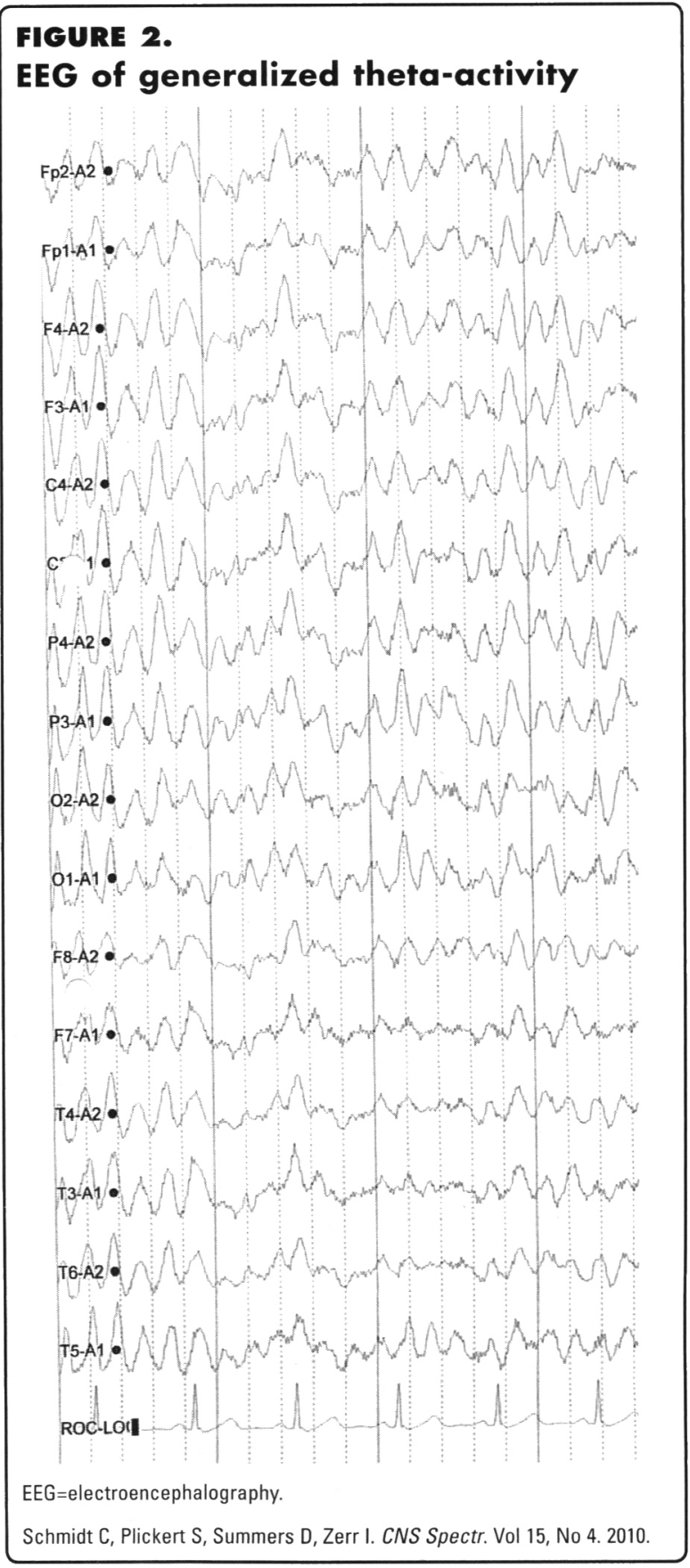

Encephalopathy. ${ }^{5}$ The patients are often young (around 30 years of age) and present with progressive psychiatric symptoms, visual disturbance, ataxia, and dementia. ${ }^{6}$ The cumulative case number is $<200$ worldwide. ${ }^{7}$ No cases of vCJD in Germany have been identified. The pulvinar sign is one of the core diagnostic features of vCJD. ${ }^{8}$ It is characterized by bilaterally hyperintense pulvinar nuclei of thalamus on FLAIR or diffusion-weighted MRI images. Hyperintensity is defined in relation to the signal of the basal ganglia. ${ }^{9}$ It has a sensitivity of $78 \%$ to $90 \%$ and a specificity of $100 \%$ for VCJD in the correct clinical context. ${ }^{10}$ The radiological differential diagnoses of the pulvinar sign comprise Alper's Syndrome, cat-scratch disease, postinfectious encephalitis, and others. ${ }^{8}$ It may also occur in M/V2 subtype of sporadic CJD, ${ }^{11,12}$ thalamic infarctions, and top-of-the-basilar ischemia. Hyperintense medial thalami in MRI FLAIR have been described in WE in a few case reports. ${ }^{13-15}$

WE is a neurologic condition characterized by ataxia, nystagmus, defects of ocolumotor function, and mental status changes. ${ }^{16}$ The prevalence of WE is estimated to range between $0.3 \%$ to $0.8 \%$ in Germany. ${ }^{17}$ It is caused by thiamine (vitamin B1) deficiency most commonly in malnourished patients, often those abusing alcohol. Additional symptoms of Korsakov's psychosis might be present as well. Thiamine deficiency can also cause Beriberi disease. Tachycardia, dysphonia, and tetraparesis with areflexia being present in this case might have been signs of overlapping Beriberi and therefore, because atypical in $V C J D$, were important differential diagnostic signs.

The patient described had no history of alcohol misuse. Given this fact, WE was not considered as the primary differential diagnosis. The thiamine levels determined were low, but always within the normal range. Testing for erythrocyte transketolase activity revealed it to be decreased indicating WE. This thiamine dependent enzyme is involved in the pentose phosphate pathway. ${ }^{18}$ It is possible that patients are genetically predisposed to WE. ${ }^{17}$ Prolonged dysphagia may be the first symptom of WE in a non-alcoholic patient. ${ }^{19}$ Since the thiamine reserve lasts for $\sim 18$ days after complete discontinuation of thiamine intake, ${ }^{17}$ we suspect the patient suffered from dysphagia due the tonsillectomy, and hence did not drink or eat properly. It may have persisted after discharge from the otorhinolaryngology department as the 
initial symptom of WE. This possibly genetically predisposed patient then entered a vicious cycle of dysphagia and malnutrition.

\section{CONCLUSION}

It is easy to be mislead by isolated diagnostic findings, such as the apparent pulvinar sign in this case, to suspect vCJD. Misdiagnoses of fatal diseases result in far reaching consequences for the patient and relatives. The laboratory and imaging findings in VCJD should always be interpreted in the context of all the available clinical information. This requires thorough identification and exclusion of potentially reversible causes of encephalopathies. WE should always be considered a treatable differential diagnosis of VCJD. CNS

\section{Sincerely,}

Christian Schmidt, MD

Steffen Plickert, MD

David Summers, MD

and Inga Zerr, MD, PhD

\section{REFERENCES}

1. Harvey F.J. Skelton-Robinson M, Rossor MN. The prevalence and causes of dementia in people under the age of 65 years. J Neurol Neurosurg Psychiatry. 2003;74:1206-1209.
2. Brown P. Transmissible spongiform encephalopathy in the 21st century: neuroscience for the clinical neurologist. Neurology. 2008:70:713-722.

3. Wadsworth JDF, Collinge J. Update on human prion disease. Biochim Biophys Acta. 2007:1772:598-609

4. Peden AH, Head MW, Ritchie DL, Bell JE, Ironside JW. Preclinical vCJD after blood transfusion in a PRNP codon 129 heterozygous patient. Lancet. 2004:364:527-529

5. Will RG, Ironside JW, Zeidler M, et al. A new variant of Creutzfeldt-Jakob disease in the UK. Lancet. 1996:347:921-925.

6. Zeidler M, Stewart GE, Barraclough CR, et al. New variant Creutzfeldt-Jakob disease: neurological features and diagnostic tests. Lancet. 1997;350:903-907.

7. The European and Allied Countries Collaborative Study Group of CND (EUROC.JD). htttp.// unw.eurocid.ed.ac.uk/vcjdworldeuro.htm. Accessed: March 5, 2010

8. Zeidler M, Sellar RJ, Collie DA, et al. The pulvinar sign on magnetic resonance imaging in variant Creutzfeldt-Jakob disease. Lancet. 2000;355:1412-1418.

9. Summers DM, Collie DA, Zeidler M, Will RG. The pulvinar sign in variant CreutzfeldtJakob disease. Arch Neurol. 2004:61:446-447.

10. Tschampa HJ, Zerr I, Urbach H. Radiological assessment of Creutzfeldt-Jakob disease. Eur Radiol. 2007:17:1200-1211.

11. Hak S, Brandel JP, Oppenheim C, et al. Sporadic CJD clinically mimicking variant CJD with bilateral increased signal in the pulvinar. Neurology. 2002;58:148-149.

12. Krasnianski A, Schulz-Schaeffer WJ, Kallenberg K, et al. Clinical findings and diagnostic tests in the MV2 subtype of sporadic CJD. Brain. 2006;129/Pt 9):2288-2296

13. Nolli M, Barbieri A, Pinna C, Pasetto A, Nicosia F. Wernicke's encephalopathy in a malnourished surgical patient: clinical features and magnetic resonance imaging. Acta Anaesthesiol Scand. 2005;49:1566-1570.

14. Doss $A$, Mahad D. Romanowski CAJ: Wernicke encephalopathy: unusual findings in non-alcoholic patients. J Comput Assist Tomogr. 2003:27:235-240.

15. Weidauer $S$, Nichtweiss $M$, Lanfermann $H$, Zanella FE. Wernicke encephalopathy: MR findings and clinical presentation. Eur Radiol. 2003:13:1001-1009.

16. Donnino MW, Vega J, Miller J, Walsh M. Myths and misconceptions of Wernicke's encephalopathy: what every emergency physician should know. Ann Emerg Med. 2007;50:715-721

17. Sechi G, Serra A. Wernicke's encephalopathy: new clinical settings and recent advances in diagnosis and management. Lancet Neurol. 2007;6:442-455.

18. Pearce JMS. Wernicke-Korsakoff encephalopathy. Eur Neurol. 2008;59:101-104

19. Karaiskos I, Katsarolis I, Stefanis L. Severe dysphagia as the presenting symptom of Wernicke-Korsakoff syndrome in a non-alcoholic man. Neurol Sci. 2008;29:45-46.

Dr. Schmidt is a resident in neurology at Georg August University of Goettingen Medical School, German National Reference Center for the Surveilance of Prion Diseases in Goettingen. Germany. Dr. Plickert is attending/senior physician in the Department of Neurology at St. Katharinen Hospital in Frechen, Germany. Dr. Summers is an attending neuroradiologist at the University of Edinburgh Medical School in the United Kingdom. Dr. Zerr is an attending neurologist and head of the German National Reference Center for the Surveilance of Prion Diseases in Goettingen, Germany.

Faculty Disclosures: The authors do not have an affiliation with or financial interest in any organization that might pose a conflict of interest.

Funding/Support: This study was supported by grants from the Robert Koch-Institute through funds of the German Federal Ministry of Health Igrant no $1369-3411$.

Submitted for publication: March 18, 2009; Accepted for publication: July 31, 2009.

Please direct all correspondence to: Christian Schmidt, MD, Georg August University Hospital, Dept. of Neurology, Prionresearch, Robert-Koch Str. 40, D-37075 Goettingen, Germany; Tel: 49-551-398955, Fox: 49-551-397020; E-mail: Christian.Schmid@@medizin.uni-goettingen.de. 


\section{PSYCHIATRISTS, \\ YOUR PROFESSIONAL LIABILITY INSURER MAY NO LONGER BE SAFE OR SOUND.}

\section{MAKE SURE YOUR PROFESSIONAL}

\section{LIABILITY INSURANCE}

\section{IS PROVIDED BY A COMPANY}

WITH AN" "EXELIEN" RATING.

\section{AND DON'T SETTLE FOR}

DEPEND ANYTHING LESS.

Darwin National

\section{Assurance Company}

darwin

profossional
undiderwriters ine.
Darwin is rated "Excellent" by A.M. Best Co. and anticipates a further upgrade in its rating very soon not a downgrade.
Discounts

- 50\% for Part-time

- 10\% Claims free

- 50\% as a New Graduate (Please call 1-800-421-6694 for complete details on these discounts.)

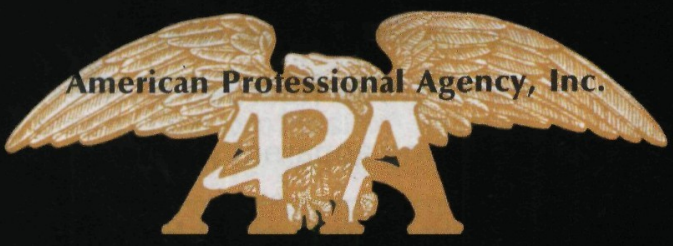

POLICY ADMINISTRATOR
Endorsed By:

AMERICAN ACADEMY OF CHILDEADOLESCENT PSYCHIATRY

95 Broadway, Amityville, NY 11701

$$
\text { 1-800-421-6694 }
$$

W.W a mericanprofessional.com 